\title{
Acute determination of plasma glycerol as a means of predicting arrhythmias in patients with myocardial ischaemia
}

\author{
S. Carlström and A. Gustafson \\ From the Departments of Internal Medicine A and Cardiology, University Hospital, Lund, Sweden
}

Capillary blood samples were taken on admission in 254 patients, referred to hospital on the suspicion of myocardial infarction, and the plasma glycerol concentration was determined.

The patients were retrospectively divided into five groups according to their diagnosis, taking into account the presence or absence of myocardial infarction and complicating arrhythmias. It was found that the mean plasma glycerol concentrations were significantly higher in the groups with complicating arrhythmias than in the groups without arrhythmias. The main correlation found was between raised plasma glycerol and complicating arrhythmias, irrespective of whether infarction was present or not. To judge from the present results, acute determination of capillary plasma glycerol in patients with suspicion of myocardial infarction may provide some clue to those who are prone to develop arrhythmias.

A previous study from our laboratory (Carlström and Christensson, 1971) indicated that patients with myocardial infarction complicated by arrhythmias had plasma glycerol concentrations higher than those with uncomplicated myocardial infarctions. This was indicated when either the mean capillary plasma glycerol concentration during the first day in hospital or the venous plasma glycerol concentration on admission were used as parameters. These findings suggested that the plasma glycerol might be used as a predicting index of arrhythmias, but the sampling procedures used have drawbacks from that point of view. The mean capillary plasma glycerol concentration was determined from three samples taken at fixed hours during the first day in hospital and thus did not include acute determinations. The use of venous blood for the glycerol determination lessens the reliability of the concentration as an index, because the venous glycerol concentration is known to vary more than the arterial and the capillary concentrations (Gordon and Cherkes, 1956).

In the present study, capillary blood samples taken immediately after admission to hospital were used, and the aim of the present study was to establish whether the capillary plasma glycerol con-

Received 8 March I974. centration could be used as a predicting index of complicating arrhythmias in patients with myocardial infarction.

\section{Subjects}

The present study includes 254 patients referred to the medical intensive care unit on the suspicion of myocardial infarction.

Patients with diabetes mellitus and those with a diagnosis of pulmonary embolism were excluded. None of the patients were given theophylline, sympathomimetic drugs, $\beta$-blocking agents, or heparin.

A diagnosis of myocardial infarction was based on typical electrocardiographic changes ( $Q$ waves and/or sequential changes of $S T$ segments and $T$ waves). The serum levels of myocardial enzymes were raised in 94 per cent of the patients with myocardial infarction.

The electrocardiogram was continuously monitored during the patient's stay in the intensive care unit by bedside oscilloscopes and at the nurse's station where it was also intermittently recorded on paper. Arrhythmias were defined as: persistent sinus tachycardia, atrial flutter or fibrillation, frequent ventricular extrasystoles, ventricular tachycardia, ventricular fibrillation, persistent sinus bradycardia, and atrioventricular block.

On the basis of clinical, electrocardiographic, and laboratory findings, the patients were retrospectively divided into five groups. Table I shows the diagnosis, sex, and age distribution of the groups. The division 
TABLE I Number, sex, and age of patients in different groups

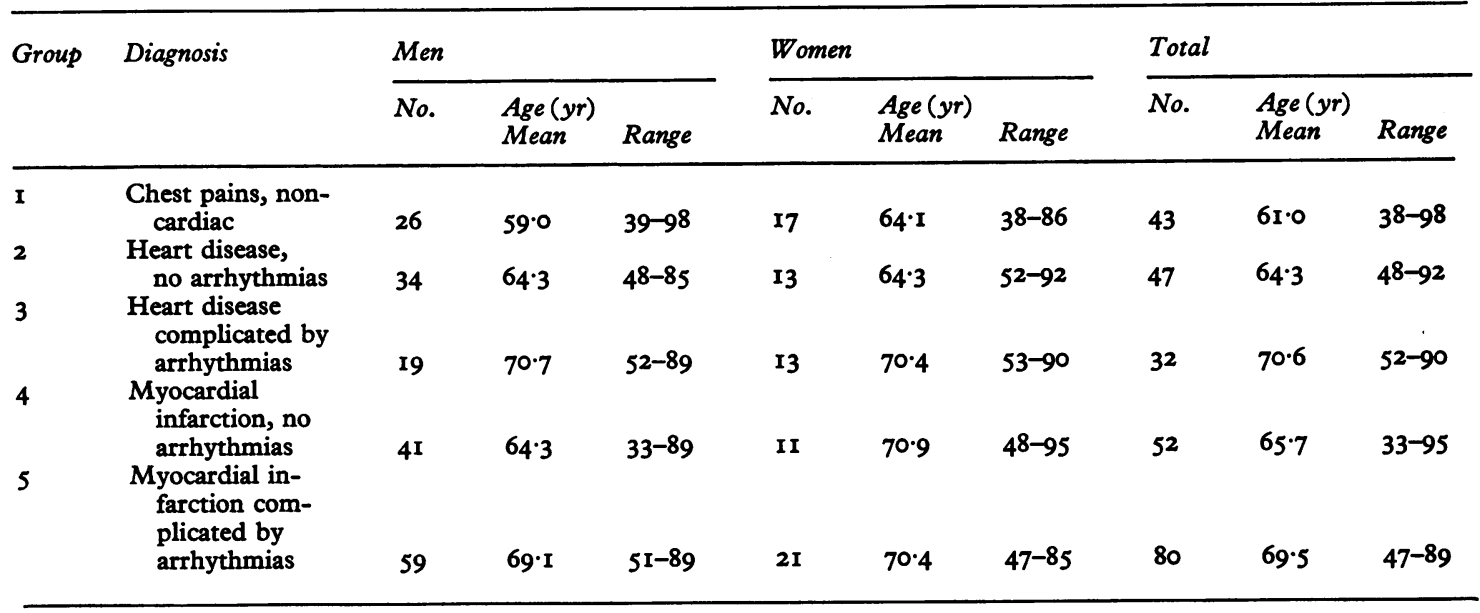

TABLE 2 Type of arrhythmia

\begin{tabular}{|c|c|c|c|c|c|c|c|c|c|c|c|c|c|c|c|}
\hline \multirow[t]{2}{*}{ Group } & \multirow[t]{2}{*}{ No. } & \multicolumn{2}{|c|}{$\begin{array}{l}\text { Sinus } \\
\text { tachycardia }\end{array}$} & \multicolumn{2}{|c|}{$\begin{array}{l}\text { Atrial flutter } \\
\text { or fibrillation }\end{array}$} & \multicolumn{2}{|c|}{$\begin{array}{l}\text { Ventricular } \\
\text { extrasystoles }\end{array}$} & \multicolumn{2}{|c|}{$\begin{array}{l}\text { Ventricular } \\
\text { tachycardia }\end{array}$} & \multicolumn{2}{|c|}{$\begin{array}{l}\text { Ventricular } \\
\text { fibrillation }\end{array}$} & \multicolumn{2}{|c|}{$\begin{array}{l}\text { Atrio- } \\
\text { ventricular } \\
\text { block }\end{array}$} & \multicolumn{2}{|c|}{$\begin{array}{l}\text { Sinus } \\
\text { bradycardia }\end{array}$} \\
\hline & & No. & $\begin{array}{l}\text { Per } \\
\text { cent }\end{array}$ & No. & $\begin{array}{l}\text { Per } \\
\text { cent }\end{array}$ & No. & $\begin{array}{l}\text { Per } \\
\text { cent }\end{array}$ & No. & $\begin{array}{l}\text { Per } \\
\text { cent }\end{array}$ & No. & $\begin{array}{l}\text { Per } \\
\text { cent }\end{array}$ & No. & $\begin{array}{l}\text { Per } \\
\text { cent }\end{array}$ & No. & $\begin{array}{l}\text { Per } \\
\text { cent }\end{array}$ \\
\hline $\begin{array}{l}3 \\
5\end{array}$ & $\begin{array}{l}32 \\
80\end{array}$ & $\begin{array}{r}\text { I } \\
13\end{array}$ & $\begin{array}{r}3 \\
16\end{array}$ & $\begin{array}{l}22 \\
16\end{array}$ & $\begin{array}{l}69 \\
20\end{array}$ & $\begin{array}{r}7 \\
40\end{array}$ & $\begin{array}{l}22 \\
50\end{array}$ & $\begin{array}{l}0 \\
\mathbf{I}\end{array}$ & $\begin{array}{l}0 \\
\text { I }\end{array}$ & $\begin{array}{l}0 \\
3\end{array}$ & $\begin{array}{l}0 \\
4\end{array}$ & $\begin{array}{l}2 \\
3\end{array}$ & $\begin{array}{l}6 \\
4\end{array}$ & $\begin{array}{l}0 \\
4\end{array}$ & $\begin{array}{l}0 \\
5\end{array}$ \\
\hline
\end{tabular}

TABLE 3 Significant differences ( $P$ values) found when comparing the plasma glycerol concentrations of the groups using Wilcoxon's rank sum test

\begin{tabular}{llllll}
\hline Group & $I$ & 2 & 3 & 4 & 5 \\
\hline$I$ & - & NS & $<0.001$ & $<0.001$ & $<0.001$ \\
2 & NS & - & $<0.001$ & NS & $<0.001$ \\
3 & $<0.001$ & $<0.001$ & - & $<0.01$ & NS \\
4 & $<0.001$ & NS & $<0.01$ & - & $<0.001$ \\
5 & $<0.001$ & $<0.001$ & NS & $<0.001$ & - \\
\hline
\end{tabular}

NS $=$ not significant.

into the different groups was random concerning the results of the glycerol determinations.

Group 3 deserves special comment: of 32 patients, 23 were admitted because of chest pain; the others had palpitations or dyspnoea.

Table 2 divides the patients in groups 3 and 5 according to the type of arrhythmia. There were obvious differences between the two groups regarding the frequencies of the different types of arrhythmia. In group 3, atrial fibrillation and flutter was the most common (69\%), followed by ventricular extrasystoles ( $22 \%$ ). In group 5 , ventricular extrasystoles was the most common arrhythmic type ( $50 \%$ ), followed by atrial fibrillation and flutter $(20 \%)$. In the last group, persistent sinus tachycardia was also common (16\%). Ventricular tachycardia and ventricular fibrillation did not appear in group 3, but was present in a few patients in group 5 ( $I$ and $4 \%$ respectively). 


\section{Methods}

Plasma glycerol was determined according to the method of Laurell and Tibbling (1966). The blood samples were kept in ice water until centrifuged. The reproducibility of the method has been given by Laurell and Tibbling to $\pm 1.7 \mu \mathrm{mol} / 1$. (SD) in plasma based on 30 pairs of duplicate analyses in the range of 40 to 180 $\mu \mathrm{mol} / \mathrm{l}$. In our laboratory, we have found the precision to be 3.I per cent (SD) in the range 44 to $320 \mu \mathrm{mol} / \mathrm{l}$. (mean $94 \mu \mathrm{mol} / \mathrm{l})$. The normal figures of plasma glycerol in the fasting state are reported to be $48 \pm 15$ (SD) $\mu \mathrm{mol} / 1$. by Laurell and Tibbling (I966). In the statistical evaluation, Wilcoxon's rank sum test was used (Wilcoxon, 1945).

\section{Results}

The Fig. summarizes the plasma glycerol values of the five groups of patients. Table 3 lists the significance levels ( $P$ values) between the groups in comparison of plasma glycerol concentrations. The glycerol concentrations of group 3 were significantly higher than those of groups $I, 2$, and 4 . The glycerol values of group 5 were significantly raised compared

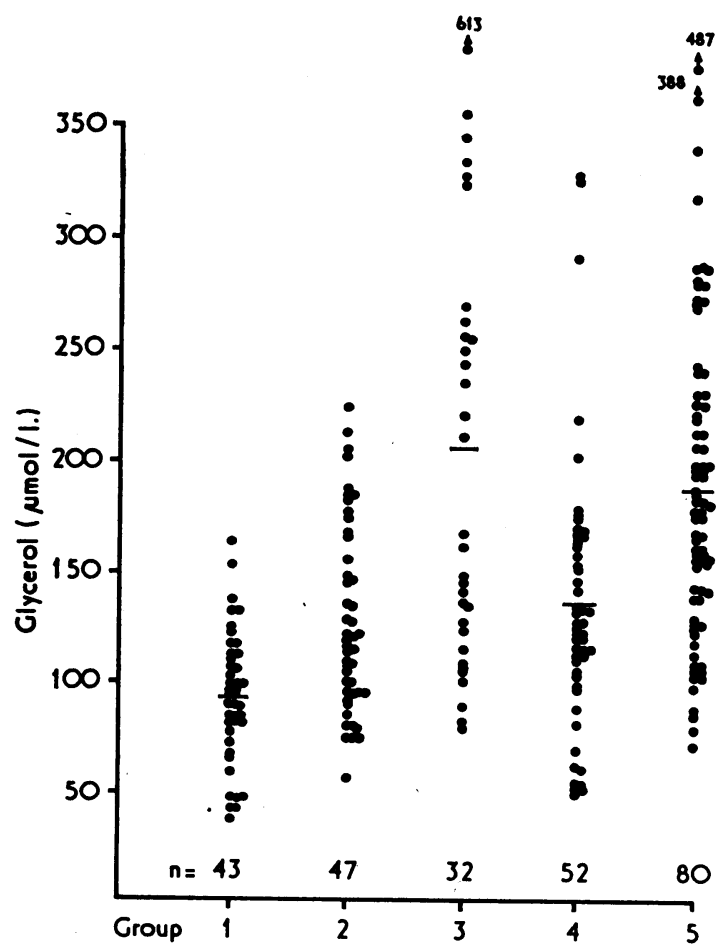

FIG. The individual capillary plasma glycerol concentrations in the patients in the five groups. Table I explains diagnostic groups $I$ to 5. Horizontal lines indicate the mean concentrations of the groups.
TABLE 4 Number and percentage of patients in the different groups with plasma glycerol concentrations exceeding $180 \mu \mathrm{mol} / \mathrm{l}$.

\begin{tabular}{llcl}
\hline \multicolumn{2}{l}{ Group } & Number & Percentage \\
\hline $\mathbf{I}$ & $(\mathrm{N}=43)$ & 0 & 0 \\
2 & $(\mathrm{~N}=47)$ & 8 & 17 \\
3 & $(\mathrm{~N}=32)$ & 15 & 47 \\
4 & $(\mathrm{~N}=52)$ & 5 & 10 \\
5 & $(\mathrm{~N}=80)$ & 38 & 48 \\
\hline
\end{tabular}

with the values of groups 1,2 , and 4. No significant difference was noted when group 3 was compared with group 5. Thus, both groups that included patients with arrhythmias showed significantly raised concentrations of capillary plasma glycerol compared with the groups without complicating arrhythmias. Those in group 4 with uncomplicated myocardial infarction showed significantly raised plasma glycerol concentrations compared with the concentrations of group I patients, who had chest pains of non-cardiac origin.

With the glycerol concentration of $180 \mu \mathrm{mol} / 1$. as an arbitrarily chosen borderline, Table 4 shows how many of the 254 patients had glycerol concentrations exceeding this level. It is apparent from the Table that very few patients in the nonarrhythmia groups (groups I, 2, and 4) had higher concentrations, whereas about 50 per cent of those in the arrhythmia groups showed higher values.

\section{Discussion}

Fatty acids and glycerol form when triglycerides in adipose tissue are broken down. This breakdown is known as lipolysis and is controlled by a hormonesensitive lipase, activated by several hormones, of which the catecholamines appear to be the most essential. The fatty acids formed may either leave adipose tissue or be reused within it, whereas glycerol cannot be reused in adipose tissue (Steinberg, 1964; Havel, 1965); it is, therefore, released to the circulating blood plasma. Thus the plasma concentration of glycerol is a fairly good indication of the rate of adipose tissue lipolysis, and also of the catecholamine activity.

The plasma free fatty acid concentration is also raised as a result of lipolysis, but as some part of the liberated fatty acids are reused in adipose tissue, the plasma free fatty acid is a less discriminating variable than plasma glycerol. This might be responsible for the divergent results published concerning the correlation between plasma free fatty acid concentration and complications of myocardial infarc- 
tion (Oliver, Kurien, and Greenwood, 1968; Rutenberg, Pamintuan and Soloff, 1969; Carlström and Christensson, I97I; Prakash et al., 1972).

The excretion of catecholamines in urine (Klein et al., 1968; Januszewicz et al., 1968; Jewitt et al., 1969; Hayashi, Moss, and Yu, I969; Valori, Thomas, and Shillingford, 1967; Prakash et al., 1972) and plasma catecholamine concentrations (Gazes, Richardson, and Woods, 1959; McDonald et al., 1969; Siggers, Salter and Fluck, 197I) have been determined in myocardial infarction, and a positive correlation has been shown to exist between raised levels of catecholamines and complications of the infarction.

Plasma cortisol concentration has also been shown to be more raised in patients with complicated myocardial infarction than in patients with uncomplicated infarction (Prakash et al., 1972). It has been proposed that the arrhythmias during acute myocardial infarction are caused by a direct deleterious effect of free fatty acid on the injured myocardium (Kurien, Yates, and Oliver, 1969; Henderson, Most, and Sonnenblick, 1969; Gupta et al., 1969; Taylor et al., 1969. However, as yet, it cannot be excluded that both the rise in plasma free fatty acid, caused by fatty acid release from adipose tissue, and the arrhythmias are effects of a rise in the plasma catecholamine level (Nelson, 1970) and are without causal interrelation.

This theory may or may not be true, but the plasma glycerol concentration is a fairly good indication of the catecholamine activity. In the present series of patients, both groups with complicating arrhythmias showed a highly significant correlation to raised levels of capillary plasma glycerol. This was true both for patients with heart disease without signs of acute myocardial injury and for patients with myocardial infarction. Thus, the main correlation was found between raised capillary plasma glycerol and complicating arrhythmias, irrespective of whether infarction was present.

In group 3, the dominant type of arrhythmia was atrial flutter or fibrillation with a lesser number of ventricular extrasystoles. The most common types of arrhythmia in the group with myocardial infarction were in order ventricular extrasystoles, atrial flutter or fibrillation, and sinus tachycardia. Despite this difference, the mean plasma glycerol concentrations of the two groups were similar. A closer study failed to reveal any differences in the plasma glycerol levels in patients with different types of arrhythmia. Nor did a closer analysis show any correlation between the plasma glycerol and signs of cardiac insufficiency.

About 50 per cent of the patients who had arrhythmias during their stay in hospital had a rise in the plasma glycerol concentration above 180 $\mu \mathrm{mol} / \mathrm{l}$. on admission to hospital, whereas on average only 9 per cent of the patients without complicating arrhythmias had plasma glycerol levels exceeding that amount. In the group with chest pains of non-cardiac origin, no patient had a glycerol value above $180 \mu$ mole $/ 1$.

To judge from the present results, acute determinations of the capillary plasma glycerol concentrations in patients with suspicion of myocardial infarctions may provide some clue to those who are prone to develop arrhythmias.

The determination of capillary plasma glycerol is easy with the method of Laurell and Tibbling (1966), and the analysis is feasible for acute determinations. The other variables, plasma cortisol and plasma catecholamines, which may also be used as predicting indices of arrhythmias, are more difficult and time consuming to estimate.

Miss Anita Jönsson's technical assistance is gratefully acknowledged. The study was supported by grants from the Swedish Research Council and from the 'Svenska Nationalföreningen mot Hjärt- och Lungsjukdomar', Stockholm, Sweden.

\section{References}

Carlström, S., and Christensson, B. (1971). Plasma glycerol concentration in patients with myocardial ischaemia and arrhythmias. British Heart fournal, 33, 884.

Gazes, P. C., Richardson, J. A., and Woods, E. F. (1959). Plasma catecholamine concentrations in myocardial infarction and angina pectoris. Circulation, 19, 657.

Gordon, R. S., and Cherkes, A. (1956). Unesterified fatty acids in human blood plasma. fournal of Clinical Investigation, 35, 206.

Gupta, D. K., Young, R., Jewitt, D. E., Hartog, M., and Opie, L. H. (1969). Increased plasma-free-fatty-acid concentrations and their significance in patients with acute myocardial infarction. Lancet, 2, 1209.

Havel, R. J. (1965). Some influences of the sympathetic nervous system and insulin on mobilization of fat from adipose tissue: Studies of the turnover rates of free fatty acids and glycerol. Annals of the New York Academy of Sciences, 131, 91.

Hayashi, K. D., Moss, A. J., and Yu, P. N. (1969). Urinary catecholamine excretion in myocardial infarction. Circulation, 40, 473.

Henderson, A. H., Most, A. S., and Sonnenblick, E. H. (1969). Depression of contractility in rat heart muscle by free fatty acids during hypoxia. Lancet, 2,825 .

Januszewicz, W., Sznahderman, M., Wocial, B., and Preibisz, J. (1968). Urinary excretion of free norepinephrine and free epinephrine in patients with acute myocardial infarction in relation to its clinical course. American Heart fournal, 76, 345 .

Jewitt, D. E., Mercer, C. J., Reid, D., Valori, C., Thomas, M., and Shillingford, J. P. (1969). Free noradrenaline and adrenaline excretion in relation to the development of cardiac arrhythmias and heart-failure in patients with acute myocardial infarction. Lancet, $x, 635$. 
Klein, R. F., Troyer, W. G., Thompson, H. K., Bogdonoff, M. D., and Wallace, A. G. (1968). Catecholamine excretion in myocardial infarction. Archives of Internal Medicine, 122, 476.

Kurien, V. A., Yates, P. A., and Oliver, M. F. (1969). Free fatty acids, heparin, and arrhythmias during experimental myocardial infarction. Lancet, 2, 185 .

Laurell, S., and Tibbling, G. (1966). An enzymatic fluorometric micromethod for the determination of glycerol. Clinica Chimica Acta, 13, 317.

Oliver, M. F., Kurien, V. A., and Greenwood, T. W. (1968). Relation between serum-free-fatty-acids and arrhythmias and death after acute myocardial infarction. Lancet, 1 , 7 Io.

McDonald, L., Baker, C., Bray, C., McDonald, A., and Restieux, N. (1969). Plasma-catecholamines after myocardial infarction. Lancet, 2, 1021.

Nelson, P. G. (1970). Free fatty acids and cardiac arrhythmias. Lancet, $1,783$.

Prakash, R., Parmley, W. W., Horvat, M., and Swan, H. J. C. (1972). Serum cortisol, free fatty acids, and urinary catecholamine as indicators of complications in acute myocardial infarction. Circulation, 45, 736.

Rutenberg, H. L., Pamintuan, J. C., and Soloff, L. A. (I969).
Serum-free-fatty-acids and their relation to complications after acute myocardial infarction. Lancet, 2, 559 .

Siggers, D. C., Salter, C., and Fluck, D. C. (197I). Serial plasma adrenaline and noradrenaline levels in myocardial infarction using a new double isotope technique. British Heart fournal, 33, 878.

Steinberg, D. (1964). Synthesis and breakdown of triglycerides in adipose tissue. In Fat as a Tissue, p. 127. Ed. by K. Rodahl and B. Issekutz. McGraw-Hill, New York.

Taylor, S. H., Saxton, C., Majid, P. A., Dykes, J. R. W., Ghosh, P., and Stoker, J. B. (1969). Insulin secretion following myocardial infarction with particular respect to the pathogenesis of cardiogenic shock. Lancet, 2, 1373.

Valori, C., Thomas, M., and Shillingford, J. (1967). Free noradrenalin and adrenalin excretion in relation to clinical syndromes following myocardial infarction. American fournal of Cardiology, 20, 605.

Wilcoxon, F. (1945). Individual comparisons by ranking methods. Biometrics, $\mathbf{1}, 80$.

Requests for reprints to Dr. S. Carlström, Research Department I, E-blocket, University Hospital, S-22I 85 Lund, Sweden. 